\title{
Some Insights into Analytical Bias Involved in the Application of Grab Sampling for Volatile Organic Compounds: A Case Study against Used Tedlar Bags
}

\author{
Samik Ghosh, ${ }^{1}$ Ki-Hyun Kim, ${ }^{1}$ and Jong Ryeul Sohn ${ }^{2}$ \\ ${ }^{1}$ Department of Environment and Energy, Sejong University, \\ Seoul 143-747, Republic of Korea \\ ${ }^{2}$ Department of Environmental Health, Korea University, \\ Seoul 136-075, Republic of Korea
}

Received 25 June 2011; Revised 23 August 2011; Accepted 23 August 2011

Academic Editor: Richard Brown

\begin{abstract}
In this study, we have examined the patterns of VOCs released from used Tedlar bags that were once used for the collection under strong source activities. In this way, we attempted to account for the possible bias associated with the repetitive use of Tedlar bags. To this end, we selected the bags that were never heated. All of these target bags were used in ambient temperature (typically at or below $30^{\circ} \mathrm{C}$ ). These bags were also dealt carefully to avoid any mechanical abrasion. This study will provide the essential information regarding the interaction between VOCs and Tedlar bag materials as a potential source of bias in bag sampling approaches.
\end{abstract}

KEYWORDS: volatile organic compounds, tedlar bag, sampling bias, polar, nonpolar 


\section{INTRODUCTION}

Volatile organic compounds (VOCs) are gaseous non-methane organic compounds (NMOCs) with carbon numbers typically varying from $\mathrm{C}_{2}$ to $\mathrm{C}_{12}$ [1]. A large fraction of VOCs have short- or long-term health effects on human beings when they exceed certain concentration levels [2]. As the chemical composition of VOCs facilitates the vaporization under normal indoor atmospheric conditions, large quantities of them can be released during various industrial processes [2].

A grab sampling method is one essential component in the analysis of VOCs. To date, canisters and bags are the most common tools used for grab sampling [3]. The containers used for grab sampling should be easy to operate, durable, and stable for a relatively long period of time. The use of sampling bags for gaseous pollutants is advantageous in many respects, most importantly ease of sampling and replicate analyses. This procedure also requires little or no additional sampling equipments like coolants, pumps, or flow meters, while it can be completed over a short period of time (e.g., within a few minutes). All these factors are also important to avoid possible alteration of the gaseous composition in grabbed samples [3]. Tedlar bags, one of the most common bag sampling methods, are made from polyvinyl fluoride (PVF) film which is chemically inert to a wide range of compounds. They are made by DuPont under the Tedlar brand name and have been commonly called Tedlar bags by practitioners. As these bags have very little tendency to sorb organic compounds, they have been used extensively in a variety of applications, especially in industrial hygiene and environmental studies $[4,5]$. Note that US EPA also recommended Tedlar bags for storing purposes (http://www.epa.gov/ttnemc01/methods/method18.html\#isd) [6].

Although the use of Tedlar bags for environmental sampling was advantageous in a number of respects, its application also suffered from several drawbacks such as out-gassing of bag material, erroneous analytical results, inconsistency in blank levels (with the type of sample components), alterations of sample concentrations due to storage, permeation of certain compounds (through the bag walls), and leaks through valves [7-11]. Recent studies also suggest that due to the chemical structure of Tedlar, the bags made of such material can readily sorb a considerable amount of highly polar compounds [12]. As such, Tedlar bags are expected to leach organic substances even after extensive cleaning [13-15]. As a certain amount of chemicals in the bag may remain as residue after analysis, manufacturing agencies and scientists recommend a single use of Tedlar bags for the trace-level (e.g., at or below ppb) analyses [9]. However, high cost of Tedlar bags and lack of proper alternative compel laboratories to use them more than once depending on the circumstances; in fact, these cases are likely to be very common in the actual practice.

Pau et al. [16] have confirmed that the loss of certain compounds from the Tedlar bag can be more prominent due to adsorptive loss rather than leaking. The sorption characteristics of different compounds vary considerably. For some compounds, sorption on the bags may proceed immediately. However, for others, it may worsen over time and may even remain permanently [5]. Recently it is also found that siloxanes sampled in the Tedlar bags with the polypropylene valve show high and stable recovery even after 30 days [17]. Hence, the rate of adsorption and release from Tedlar bags will vary to a large extent between different compounds.

In this study, we have examined the patterns of VOCs released from used Tedlar bags that were once used for the sample collection under strong source activities. In this way, we attempted to account for the possible bias associated with the repetitive use of Tedlar bags. To this end, we selected the bags that were used in ambient temperature (typically at or below $30^{\circ} \mathrm{C}$ ). These bags were also dealt with carefully to avoid any mechanical abrasion. This study will provide the essential information regarding the interaction between VOCs and Tedlar bag materials as a potential source of bias in bag sampling approaches.

\section{MATERIALS AND METHODS}

\subsection{Experimental Scheme}

In this work, the VOCs remaining in used Tedlar bags (made of Tedlar films (SKC corp., USA)) were analyzed by the combined application of the thermal desorber (TD) and the GC-MS methods. All the 10 L 
bags analyzed in this work were made up of a single polypropylene fitting with integrated septum. In order to examine VOCs released from the inner walls of Tedlar bags, each bag was cleaned consecutively for seven times using ultrapure $(99.999 \%) \mathrm{N}_{2}$. These bags were then inflated with approximately $3 \mathrm{~L}$ of pure air. The septum value of each bag was sealed hand-tight, and its gas tightness was inspected by submerging it into water. Then they were left in the laboratory overnight under the room conditions. In the very next day, each bag was analyzed for the odor intensity by a simple odor sensory test. The odor intensity test was done by inhaling a small amount of the filled air. These bags were then separated into three categories depending on the odor intensity (OI): high, medium, and low. Only the bags with high OI levels were subject to a more deliberate odor threshold evaluation stage called the air dilution sensory (ADS) test in which dilution to threshold (D/T) ratios are estimated [18]. After the ADS test, these bags were then analyzed by the TDGC-MS analysis within 24 hours. The analysis of these used bags was conducted from October 2010 to December 2010.

\subsection{Air Dilution Sensory (ADS) Test Based on the Olfactometry Method}

Both off-gassing and sorption of compounds on Tedlar bags have the potential to significantly affect sensory data. Calculating changes in the odor activity values (OAVs) for individual compounds is one way of determining overall effect of Tedlar bags on odor measurement [12]. The OAV has been used to quantify the potential contribution of individual compounds to the overall aroma $[19,20]$. In this analysis, the actual application of the ADS test was made by the standard procedure established by the Korean Ministry of Environment [21]. The KMOE method of the ADS test is based on threshold olfactometry where the central trend of odor index value is derived geometrically for a given odor sample, after excluding the outlying datasets of extreme cases [21]. This ADS test method is a modified and developed form of the triangle odor bag method of Japan [22]. The detailed procedures of the ADS test have been described in our recent study [18]. This ADS test was done by a panel of five members who were selected based on a prescreening test in which all the members were requested to distinguish samples of deionized water from testing solutions containing four chemicals with the following weight compositions (\%): acetic acid (1), TMA (0.1), methyl cyclopentenolone (3.2), and $\beta$-phenylethyl alcohol (1). All human analysts were also trained in all aspects of odor analysis employed in this study.

The bags were analysed by the ADS test to quantify the odor index values in terms of dilution to threshold (D/T) ratios, which were derived by combining the "yes/no" options of the panel members. The static dilution of odor samples for the ADS test was made in a stepwise manner by mixing original samples with odorless air using a $3 \mathrm{~L}$ odor bag made of polyethylene terephtalate film. The odorless air used for diluting odor samples was prepared by passing normal air into activated charcoal filter. The ADS test for odor samples was conducted continuously at varying dilution ranges until the last panel member reached threshold values of a given odor sample. The level of dilution for the ADS test progressed through the application of the multiplying factors derived as $X$ values:

$$
X=Z 10^{n}
$$

Here the superscripted value " $n$ " corresponds to an integer value of $0,1,2,3, \ldots, n$. In addition, $Z$ is a multiplying factor of either 1 or 3 . The odor index value for the given sample is then determined by the stipulated method [18].

\subsection{TD-GC-MS Method}

To analyze the VOC content in the used bag, a multifunctional TD system equipped with an Air Supply (AS) unit (Unity model, Markes International Ltd., UK) was interfaced with the GC-MS system. The analytes were focused on a cold trap (CT) compartment (a mixture of Carboxen 1000 and Carbopack B) at 
a temperature of $5^{\circ} \mathrm{C}$. The total length of the cold trap was $12 \mathrm{~cm}$. The outer diameter of the tube is $0.3 \mathrm{~cm}$ with an inner diameter of $0.1 \mathrm{~cm}$. In this, $6 \mathrm{~cm}$ was used to pack Carboxen 1000 and Carbopack B at $1: 1$ volume ratio. Then, the analytes were thermally desorbed at $300^{\circ} \mathrm{C}$ and transferred into the $\mathrm{GC}$ system. The basic instrumental setup of AS-TD was as follows: split ratio $=6: 1$, split flow $=5.0 \mathrm{~mL} \mathrm{~min}^{-1}$, hold time = $5.0 \mathrm{~min}$, and flow path temperature $=120^{\circ} \mathrm{C}$.

The GC-MS system used for this analysis was a Shimadzu Gas Chromatograph 2010 QP plus (Shimadzu Scientific Instrument, Japan). The mass spectrometer detector with a quadruple ion source of electron impact (EI) at $70 \mathrm{eV}$ was used with ion source temperature $200^{\circ} \mathrm{C}$, interface temperature $=200^{\circ} \mathrm{C}$, and detector threshold $100^{\circ} \mathrm{C}$. For the detection of VOCs, the total ion count (TIC) mode was applied in the TIC scan range of $35 \sim 250 \mathrm{~m} / \mathrm{z}$.

To determine the concentrations of VOCs released from each Tedlar bag, our GC system was operated at the following temperature settings: $T$ (initial): $35^{\circ} \mathrm{C}$ for $4 \mathrm{~min}, T$ (ramping): $4^{\circ} \mathrm{C} \mathrm{min}^{-1}$ rate, and $T$ (final): $200^{\circ} \mathrm{C}$ for $10 \mathrm{~min}$. For the chromatographic separation, VOCOL column $(60 \mathrm{~m} \times 0.32 \mathrm{~mm}$ I.D. and $1.8 \mathrm{~m}$ film thickness; Supelco) was used. Helium with $99.999 \%$ purity was used as carrier gas. The total running time for each cycle was set at $55.3 \mathrm{~min}$.

\subsection{Quantification of VOCs}

The quantitative analysis of VOC was made using the gaseous working standards (G-WS) of 3 aromatic VOCs (benzene, toluene, and xylene) and 4 offensive odorants (methyl ethyl ketone, isobutyl alcohol, methyl isobutyl ketone, and $n$-butyl acetate). A primary standard (PS) gas was purchased in two separate cylinders: one at $20 \mathrm{ppm}$ for benzene, toluene, and xylene and the other at $10 \mathrm{ppm}$ for methyl ethyl ketone, isobutyl alcohol, methyl isobutyl ketone, and $n$-butyl acetate (Ri Gas, Dae Jeon, Korea). Many of these selected compounds (except isobutyl alcohol, methyl isobutyl ketone, and $n$-butyl acetate) belong to the 26 target compounds that we have designated as the dominant components released from used Tedlar bags. For the estimation of all the miscellaneous VOCs (without standards), a relationship was established for seven VOCs with standards (benzene, toluene, xylene, methyl ethyl ketone, isobutyl alcohol, methyl isobutyl ketone, and $n$-butyl acetate) in terms of their slope ratios against toluene normalized carbon number derived by a four-point calibration $(40,80,160$, and $800 \mathrm{ppb})$ of standard gases [23]. Such a relationship expressed in terms of the regression equation was used to roughly estimate concentrations of other VOCs detected by our GC-MS system. For the preparation of G-WS, the PS was mixed proportionally with $\mathrm{N}_{2}$ in a $10 \mathrm{~L}$ Tedlar bag. This mixing stage for G-WS was completed by a single-step dilution of the PS to the desired concentration with the aid of a gas-tight syringe. The detection limit (DL) values of VOCs were estimated in the sub ppb range (e.g., $0.05 \mathrm{ppb}$ (or $0.23 \mathrm{ng}$ ) for $p$-xylene to $0.19 \mathrm{ppb}$ (or $0.56 \mathrm{ng}$ ) for i-BuAl) by considering the minimal peak area distinguishable from noise. The RSE values were below the 5\% level (except isobutyl alcohol (i-BuAl), with $6.06 \%$ ) based on a triplicate analysis of a $50 \mathrm{ppb}$ gaseous standard mixture of those 7 key species used for calibration.

\section{RESULTS AND DISCUSSION}

\subsection{General Features of the VOC Blank Levels in the Used Tedlar Bags}

In our experiment, we analyzed 26 bags used one time previously under a strong source environment to define possible patterns of VOC leaching from the used Tedlar bags. The used bags analyzed for this study were mainly employed for the collection of polluted air samples from diverse industrial sources (refer to Kim and Park [18] for general source types under consideration). As the initial analysis of these bags was made for the quantification of malodorous sulfur compounds, we did not match the results of initial bags with those derived for VOC in the present study. However, almost all of these bags were free from RSC blank effects, when reanalyzed for their RSE blank levels. Initially up to a total of 139 VOCs were identified 
from these target bags. Of them, 25 compounds were selected for detailed analysis, as they were measured more frequently than others, for example, above the detection limit (DL) in 10 out of 26 bags (Table 1).

Concentrations of individual compounds, along with total VOC (TVOC: sum of 25 target VOCs in this work) and $\mathrm{D} / \mathrm{T}$ values, are given in Table 2. A list of VOCs including toluene, $p$-xylene, methyl ethyl ketone, acetaldehyde, ethyl alcohol, isopropyl alcohol, acetone, acetonitrile, ethyl acetate, and tetrahydrofuran was found in a large number of bags (equal to or more than 23 among 26 bags). Except toluene, the dominant portions of those VOCs are polar compounds. Nonpolar compounds are on the other hand generally seen to be detected less frequently and in low abundance (except toluene). The mean concentrations of individual components are hence compared after being divided into polar and nonpolar families (Figure 1). Statistical summary of the major compounds measured from those Tedlar bags is also given in Table 3. It is found that the concentration levels of TVOC measured from all the bags averaged $21.1 \pm 45.3 \mathrm{ppmC}$ (mean and standard deviation), with a range of 1.5 to $174 \mathrm{ppmC}$. If the mean concentrations of individual compounds are compared, polar compounds generally exhibit relatively large values such as methyl ethyl ketone $(1.46 \pm 4.76 \mathrm{ppm})$, ethyl alcohol $(1.46 \pm 6.97 \mathrm{ppm})$, and ethyl acetate $(1.15 \pm 3.35 \mathrm{ppm})$. The means for other polar compounds were found in a moderate range: acetonitrile (364 ppb), n-pentanal (164.1 ppb), 3-methylbutanal (152.3 ppb), butanal (108 ppb), acetamide $(106 \mathrm{ppb})$, acetone $(85.9 \mathrm{ppb})$, and phenol $(88.0 \mathrm{ppb})$. The remaining polar compounds are generally found at relatively low concentration levels: isopropyl alcohol (47.7 ppb), dichloromethane (46.2 ppb), tetrahydrofuran $(25.1 \mathrm{ppb})$, and acetaldehyde $(19.1 \mathrm{ppb})$. Several polar compounds like acetaldehyde, ethyl alcohol, dichloromethane (DC), acetamide, and phenol were quantified in all the bags that we analyzed. Among the five compounds quantified in all the bags, acetamide and phenol are well known to originate (internally) from the Tedlar film [24-27]. Concentrations of acetamide were in the range of 28.6 to $380 \mathrm{ppb}$, whereas that of phenol was 0.06 to $334 \mathrm{ppb}$. It is striking to note that the concentration of nonpolar toluene $(448 \mathrm{ppb})$ is also fairly high in contrast to the other nonpolar ones. Most nonpolar compounds were consistently seen at a fairly low range of $3.80 \mathrm{ppb}$ (dioxalane) to $23.5 \mathrm{ppb}$ ( $p$-xylene).

\subsection{Frequency Distribution of VOC Leached from Tedlar Bags}

The frequency distribution of all target compounds is plotted to examine the relative pattern of leaching between different compounds in the bags (Figure 2). According to this analysis, all target compounds can be sorted into two groups. The compounds with the maximum frequency occurring at low concentration levels (e.g., below $1 \mathrm{ppb}$ ) are assigned as the first group (Figure 2(a)). For these compounds, not many bags are found to have maximum concentrations exceeding $10 \mathrm{ppb}$. In contrast, the second group is characterized with frequent occurrences at enhanced concentration levels (e.g., approximately an order of magnitude higher: Figure 2(b)). It is seen that all nonpolar compounds (except toluene) and some polar compounds (like acetic acid, butanal, 3-methylbutanal, and $n$-pentanal) can be sorted as the first type of group (reduced concentration level below $10 \mathrm{ppb}$ ). Among the compounds of the first type, some polar compounds (like $n$-pentanal, acetic acid, and 3-methylbutanal) are also found below $1 \mathrm{ppb}$ in many bags (e.g., $n \geq 16$ ). For acetic acid, the highest concentration found from all those bags was as low as $5.98 \mathrm{ppb}$, as it maintained the lowest concentration among all target compounds. According to a statistical summary (Table 3), all these three compounds are above their detection limit in 11 out of 26 bags. The low abundance of certain polar compounds is suspected to have come from their low abundance in the original field samples we had collected. For many nonpolar compounds, their frequency distribution was evenly distributed in the range of 0 to $10 \mathrm{ppb}$. However, $n$-dodecane is found to exceed more than $10 \mathrm{ppb}$ in 8 bags, followed by 3 -methylbutanal (7 bags), isobutene and $n$-pentanal (both 6 bags), butanal (5 bags), and so on. For all other polar compounds (except the three mentioned in type 1), their frequency distribution is generally high in the range below $100 \mathrm{ppb}$ with the least occurrence at or below the $10 \mathrm{ppb}$ range. Their frequency is evenly distributed without any distinctive pattern (e.g., within $100 \mathrm{ppb}$ ). The concentrations of acetonitrile are found to exceed $100 \mathrm{ppb}$ in 25 out of the 26 bags we analyzed. Interestingly, polarity of acetonitrile is also found to be the highest (dipole moment: $\mu=3.84 \mathrm{D}$ ) among all our target compounds. As the second 
TABLE 1: Basic information of the target volatile organic compounds (VOCs) investigated in this study.

(a) Polar compounds

\begin{tabular}{|c|c|c|c|c|c|}
\hline Order & Compounds & Acronym & Formula & CAS & Structure \\
\hline 1 & Acetaldehyde & AA & $\mathrm{C}_{2} \mathrm{H}_{4} \mathrm{O}$ & $75-7-0$ & \\
\hline 2 & Acetamide & ATM & $\mathrm{C}_{2} \mathrm{H}_{5} \mathrm{NO}$ & $60-35-5$ & \\
\hline 3 & Acetic acid & $\mathrm{AAD}$ & $\mathrm{C}_{2} \mathrm{H}_{4} \mathrm{O}_{2}$ & $64-19-7$ & \\
\hline 4 & Acetone & AT & $\mathrm{C}_{3} \mathrm{H}_{6} \mathrm{O}$ & $67-64-1$ & \\
\hline 5 & Acetonitrile & AN & $\mathrm{C}_{2} \mathrm{H}_{3} \mathrm{~N}$ & $75-05-8$ & \\
\hline 6 & Butanal & $\mathrm{BT}$ & $\mathrm{C}_{4} \mathrm{H}_{8} \mathrm{O}$ & $123-72-8$ & \\
\hline 7 & Dichloromethane & DC & $\mathrm{CH}_{2} \mathrm{Cl}_{2}$ & $75-09-2$ & \\
\hline 8 & Ethyl acetate & EAC & $\mathrm{C}_{4} \mathrm{H}_{8} \mathrm{O}_{2}$ & $141-78-6$ & \\
\hline 9 & Ethyl alcohol & EA & $\mathrm{C}_{2} \mathrm{H}_{5} \mathrm{OH}$ & $64-17-5$ & \\
\hline 10 & Isopropyl alcohol & IA & $\mathrm{C}_{3} \mathrm{H}_{8} \mathrm{O}$ & $67-63-0$ & \\
\hline 11 & 3-methylbutanal & MB & $\mathrm{C}_{5} \mathrm{H}_{10} \mathrm{O}$ & $390-86-3$ & \\
\hline 12 & Methyl ethyl ketone & MEK & $\mathrm{C}_{4} \mathrm{H}_{8} \mathrm{O}$ & 78-93-3 & \\
\hline 13 & $n$-pentanal & PT & $\mathrm{C}_{5} \mathrm{H}_{10} \mathrm{O}$ & $110-62-3$ & \\
\hline 14 & Phenol & $\mathrm{PH}$ & $\mathrm{C}_{6} \mathrm{H}_{6} \mathrm{O}$ & $108-95-2$ & \\
\hline 15 & Tetrahydrofuran & THF & $\mathrm{C}_{4} \mathrm{H}_{8} \mathrm{O}$ & $109-99-9$ & \\
\hline
\end{tabular}


(b) Nonpolar compounds

\begin{tabular}{|c|c|c|c|c|c|}
\hline Order & Compounds & Acronym & Formula & CAS & Structure \\
\hline 1 & Benzene & B & $\mathrm{C}_{6} \mathrm{H}_{6}$ & $71-43-2$ & \\
\hline 2 & Carbonyl sulfide & COS & $\mathrm{COS}$ & $463-58-1$ & $\mathrm{O}=\mathrm{C}=\mathrm{S}$ \\
\hline 3 & Dioxolane & DO & $\mathrm{C}_{3} \mathrm{H}_{6} \mathrm{O}_{2}$ & 646-06-0 & \\
\hline 4 & Ethylbenzene & EB & $\mathrm{C}_{8} \mathrm{H}_{10}$ & $100-41-4$ & \\
\hline 5 & Isobutene & IB & $\mathrm{C}_{4} \mathrm{H}_{8}$ & $115-11-7$ & \\
\hline 6 & Methyl acetate & MA & $\mathrm{C}_{3} \mathrm{H}_{6} \mathrm{O}_{2}$ & $79-20-9$ & \\
\hline 7 & $n$-Dodecane & DD & $\mathrm{C}_{12} \mathrm{H}_{26}$ & $112-40-3$ & \\
\hline 8 & $n$-Octane & OT & $\mathrm{C}_{8} \mathrm{H}_{18}$ & 111-65-9 & \\
\hline 9 & $p$-Xylene & $\mathrm{p}-\mathrm{X}$ & $\mathrm{C}_{8} \mathrm{H}_{10}$ & $106-42-3$ & \\
\hline 10 & Toluene & $\mathrm{T}$ & $\mathrm{C}_{7} \mathrm{H}$ & $108-88-33$ & \\
\hline
\end{tabular}

strong polar compound among our target compounds, acetamide $(\mu=3.72 \mathrm{D})$ is found to exceed $100 \mathrm{ppb}$ with the second highest frequency (12 bags). Other highly polar compounds like acetone $(\mu=2.91 \mathrm{D})$ and phenol $(\mu=1.70 \mathrm{D})$ are also found above $100 \mathrm{ppb}$ from 9 and 8 bags, respectively. Thus, based on the frequency distribution analysis, it is clear that polar compounds are generally leached more efficiently than the nonpolar compounds.

\subsection{Relationship among VOC Concentration, TVOC, and ADS Test}

The usefulness of human sensory method such as the ADS test is well known as a supplementary tool to determine malodor strengths via assessment of dilution to threshold (D/T) ratios [24, 27, 28]. According to our previous study, concentration data of offensive odorants determined from polluted sources can maintain strong relationships with odor intensity derived from human sensory test [18]. The results of the ADS test, expressed as a D/T ratio, are found to vary in a wide range from 44.8 to 2080 with a mean of $323 \pm 503$ (Table 3). An abnormally high D/T ratio value (2080) from one bag may be due to high concentrations of 3-methylbutanal $(1028 \mathrm{ppbC})$, which is widely known for its strong banana-like odor (http://partsregistry.org/Part:BBa_J45900:Experience). Another bag with moderately high D/T value (557) is likely to be supported by high concentrations of phenol (390 ppbC) with a strong sweet odor (http://www.deq.state.ne.us/Publica.nsf/0/e656e6716113cacd05256c55007a3dc0?OpenDocument). Interestingly, in both of these bags, the TVOC values were not that high (6.5 and $2.5 \mathrm{ppmC}$, resp.), compared to their $\mathrm{D} / \mathrm{T}$ values. Overall, the $\mathrm{D} / \mathrm{T}$ value is not necessarily (directly) correlated with the concentration 
TABLE 2: Concentrations of individual compounds (in $\mathrm{ppbC}$ unit) along with TVOC concentration and D/T values.

(a) Polar compounds

\begin{tabular}{|c|c|c|c|c|c|c|c|c|c|c|c|c|c|c|c|}
\hline & & TM & $\mathrm{AD}$ & $\mathrm{AT}$ & AN & BT & DC & EAC & EA & IA & MB & MEK & PT & $\mathrm{PH}$ & THF \\
\hline 1 & 5.9 & 761 & 61 & 17 & 591 & .51 & 35.7 & 36072 & 116 & 1863 & 0.42 & 31894 & 0.42 & 1170 & .51 \\
\hline & & 26 & & 5 & S & & & & & & & & & 11 & \\
\hline & & 81 & & 29 & 9 & 51 & 66.5 & & & 3 & 42 & & 42 & 83 & 169 \\
\hline 2 & 7.0 & 236 & 2.0 & 121 & 499 & 0.51 & 25.4 & 18. & 49.1 & 88.0 & 0.42 & 28.5 & 0.42 & 85 & 28.0 \\
\hline & & 7.8 & & 474 & 537 & 9.3 & 65.5 & & & 0.1 & & & 26.6 & 236 & 11 \\
\hline ( & 1 & 322 & .09 & 12 & 1089 & 5.2 & 86.5 & & & .8 & .9 & & 42 & 42 & 210 \\
\hline T & .1 & 66.5 & 0.61 & 124 & 604 & 3.04 & 30.9 & 8.3 & 44.0 & 35.6 & 0.42 & 9.40 & 0.42 & 413 & 33.0 \\
\hline & & 257 & & 22 & 862 & 33.7 & 29.4 & & & 0.6 & 34.4 & & 0.42 & 1074 & 39.6 \\
\hline 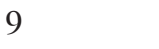 & & 3.4 & & & 7 & 5 & 26.5 & & & & 91 & & & 07 & 0.51 \\
\hline 10 & .8 & 223 & 0.61 & 337 & 597 & 0.51 & 54.9 & & 197 & 49.7 & 0.42 & .6 & 0.42 & 716 & 116 \\
\hline 11 & 8 & 237 & 7. & 241 & 850 & 10.7 & 40.5 & 3.9 & 60.5 & 38.3 & 15.0 & 2 & 0.42 & 390 & 125 \\
\hline & & 10 & & & 7 & 56 & 44.3 & & & & & & & 55 & 9.8 \\
\hline 1. & 8 & 310 & 0.6 & 341 & 985 & 0.51 & 75.7 & 56321 & 121 & 34 & 0.42 & 224 & 0.42 & 695 & 86.3 \\
\hline 14 & 8 & 156 & .03 & 172 & 836 & 545 & 37.8 & 0.4 & 48.8 & 17.5 & 441 & 6.11 & 1224 & 281 & 36.5 \\
\hline 1. & & 8.4 & & 222 & 67 & 1 & 40.5 & & & & & & & 52 & 8.6 \\
\hline 16 & & 7.1 & & 0.63 & 61 & 3869 & 36.4 & & & 17 & & & & 111 & 28.3 \\
\hline 17 & 8.0 & 144 & 4.60 & 138 & 715 & 0.51 & 34.1 & 1018 & 44.5 & 170 & 0.42 & 00 & 0.42 & 350 & 23.9 \\
\hline 18 & 49 & 108 & & 236 & 561 & 25.9 & 31.7 & & 40.3 & 22.2 & 1074 & .9 & & 277 & 37.8 \\
\hline 10 & & 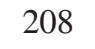 & & & 78 & 1 & 35.9 & & & & & & & 0.39 & 55.1 \\
\hline 20 & 36.5 & 213 & 2.5 & 88 & 758 & 46.6 & 32.5 & 28.9 & 43.2 & 34.6 & 11083 & 163 & 85 & 329 & 28.8 \\
\hline 21 & 26.1 & 229 & 0.61 & 213 & 55 & 6.98 & 47.2 & 268 & 454 & 79.3 & 39.7 & 45.5 & 12.2 & 486 & 161 \\
\hline 22 & & 118 & 0.61 & 203 & 544 & 0.51 & 47.8 & & 481 & 81.0 & 0.42 & & & 311 & 154 \\
\hline 23 & 12.7 & 157 & 0.61 & 434 & 1600 & 0.51 & 72.1 & 77 & 106 & 137 & 0.42 & 15.1 & 3.49 & 43 & 435 \\
\hline 24 & 10.3 & 6.7 & 2.50 & 322 & 967 & 0.51 & 67.1 & 78.6 & 119 & 97.9 & 0.42 & 8.81 & 0.42 & 150 & 256 \\
\hline 25 & 18.2 & 189 & 0.61 & 245 & 732 & 0.51 & 41.6 & & 59.9 & 52.3 & 0.42 & 9.17 & 0.42 & 407 & 142 \\
\hline 26 & 140 & 505 & .01 & 119 & 475 & 0.51 & 15.0 & 24308 & 71349 & 74.7 & 0.42 & 28906 & 0.42 & 2005 & 33.9 \\
\hline
\end{tabular}

(b) Nonpolar compounds

\begin{tabular}{lcccccccccccc}
\hline Sample no. & ${\mathrm{D} / \mathrm{T}^{\mathrm{b}}}$ & TVOC $^{\mathrm{c}}$ & $\mathrm{B}^{\mathrm{a}}$ & $\mathrm{COS}$ & $\mathrm{DO}$ & $\mathrm{EB}$ & $\mathrm{IB}$ & $\mathrm{MA}$ & $\mathrm{DD}$ & $\mathrm{OT}$ & $\mathrm{p}-\mathrm{X}$ & $\mathrm{T}$ \\
\hline 1 & - & 114771 & 0.42 & 0.61 & 0.49 & 0.34 & 0.65 & 0.49 & 220 & 0.32 & 0.43 & 41780 \\
2 & 118 & 3977 & 10.9 & 0.61 & 34.7 & 47.0 & 86.4 & 23.7 & 541 & 0.32 & 41.9 & 260 \\
3 & 373 & 3449 & 11.1 & 0.61 & 24.0 & 31.3 & 0.65 & 20.6 & 0.21 & 0.32 & 39.8 & 174 \\
4 & 44.8 & 2631 & 32.0 & 4.76 & 0.49 & 20.5 & 0.65 & 0.49 & 88.4 & 0.32 & 61.2 & 313 \\
5 & - & 2797 & 18.0 & 0.61 & 44.1 & 21.5 & 0.65 & 24.9 & 0.21 & 0.32 & 26.3 & 135 \\
6 & 118 & 4983 & 0.42 & 0.61 & 15.4 & 35.7 & 0.65 & 40.9 & 0.21 & 0.32 & 48.0 & 144 \\
7 & - & 1503 & 2.03 & 5.30 & 0.49 & 0.34 & 14.5 & 11.4 & 73.0 & 0.32 & 3.97 & 0.41 \\
8 & 120 & 4459 & 178.2 & 3.25 & 0.49 & 51.4 & 54.2 & 148 & 60.5 & 0.32 & 85.6 & 212 \\
9 & - & 20709 & 48.0 & 0.61 & 7.41 & 0.34 & 0.65 & 0.49 & 47.3 & 28.3 & 100 & 205 \\
10 & 250 & 3488 & 9.78 & 0.61 & 37.5 & 51.6 & 35.5 & 12.8 & 518 & 5.86 & 39.4 & 238 \\
\hline
\end{tabular}


(b) Continued.

\begin{tabular}{lcccccccccccc}
\hline Sample no. & $\mathrm{D} \mathrm{T}^{\mathrm{b}}$ & TVOC $^{\mathrm{c}}$ & $\mathrm{B}^{\mathrm{a}}$ & $\mathrm{COS}$ & $\mathrm{DO}$ & $\mathrm{EB}$ & $\mathrm{IB}$ & $\mathrm{MA}$ & $\mathrm{DD}$ & $\mathrm{OT}$ & $\mathrm{p}-\mathrm{X}$ & $\mathrm{T}$ \\
\hline 11 & 557 & 2572 & 20.5 & 10.8 & 17.0 & 20.1 & 28 & 7.94 & 80.9 & 48.0 & 16.3 & 80.4 \\
12 & 65.8 & 2103 & 288 & 5.56 & 0.49 & 9.86 & 30.2 & 0.49 & 121 & 0.32 & 21.2 & 104 \\
13 & 250 & 174092 & 0.42 & 23.1 & 40.5 & 0.34 & 30.2 & 0.49 & 0.21 & 159 & 0.43 & 24298 \\
14 & 208 & 4016 & 8.14 & 9.16 & 13.9 & 0.34 & 0.65 & 0.49 & 59.9 & 43.87 & 14.3 & 42.3 \\
15 & 2080 & 6585 & 13.2 & 5.76 & 13.8 & 0.34 & 0.65 & 0.49 & 54.1 & 0.32 & 21.9 & 47.6 \\
16 & - & 14099 & 24.6 & 6.95 & 0.49 & 0.34 & 41.1 & 0.49 & 0.21 & 0.32 & 35.7 & 57.3 \\
17 & - & 14195 & 49.7 & 11.9 & 0.49 & 1103 & 28.3 & 6.18 & 78.2 & 678 & 3950 & 5528 \\
18 & 250 & 2978 & 0.42 & 7.38 & 22.8 & 0.34 & 36.3 & 0.49 & 88.4 & 34.6 & 7.27 & 43.4 \\
19 & - & 3161 & 12.4 & 7.95 & 0.49 & 986 & 34.2 & 4.52 & 16.5 & 40.2 & 290 & 152 \\
20 & - & 13670 & 0.42 & 4.21 & 0.49 & 0.34 & 0.65 & 0.49 & 91.2 & 36.5 & 8.53 & 54.2 \\
21 & - & 2784 & 0.42 & 0.61 & 0.49 & 13.8 & 0.65 & 22.1 & 0.21 & 0.32 & 20.6 & 100 \\
22 & 144 & 2275 & 0.42 & 0.61 & 0.49 & 11.1 & 0.65 & 13.0 & 0.21 & 0.32 & 15.8 & 105 \\
23 & - & 4203 & 5.00 & 0.61 & 8.13 & 13.8 & 91.5 & 4.41 & 479 & 48.7 & 19.7 & 138 \\
24 & - & 2682 & 3.46 & 0.61 & 6.81 & 7.68 & 110 & 3.89 & 221 & 35.2 & 12.2 & 115 \\
25 & 208 & 2442 & 5.87 & 0.61 & 7.73 & 10.5 & 76.8 & 0.49 & 249 & 34.4 & 13.0 & 123 \\
26 & 65.8 & 135404 & 0.42 & 6.70 & 0.49 & 0.34 & 0.65 & 0.49 & 398 & 0.32 & 0.43 & 7063 \\
\hline
\end{tabular}

${ }^{\mathrm{a}}$ For acronyms see Table 1.

${ }^{\mathrm{b}} \mathrm{D} / \mathrm{T}$ : Dilution to threshold ratio. (For some bags, D/T ratio was not measured and show with "_-" marking.)

${ }^{\mathrm{c}}$ TVOC: Total VOC (sum of 25 target VOCs in this study) in ppmC.

of the ingredient compounds (in most cases, low negative $r$ values are observed with $P$ value around 0.5). In some cases, extremely poor $P$ values are observed for some polar compounds (e.g., methyl ethyl ketone, acetone, acetonitrile, dichloromethane, ethyl acetate, tetrahtdrofuran, and 3-methylbutanal). It is thus possible to infer that very high concentrations of certain compounds in one bag may determine the overall trend probably due to the masking effect.

To understand the factors regulating VOC levels in bags, the relationships between different parameters can be examined in a number of respects (Table 2). If TVOC levels of certain bags are observed at relatively high concentrations, they are also supported by high concentrations of certain compounds. For example, one bag with high TVOC value $(174 \mathrm{ppmC})$ tends to match high concentration of toluene (24.2 ppm) (Table 3). Likewise, such relationship was also seen from methyl ethyl ketone (90.2 ppm) or ethyl acetate (56.3 ppmC). The $\mathrm{D} / \mathrm{T}$ ratio in this bag was however found in a moderate range (250). This observed $\mathrm{D} / \mathrm{T}$ ratio should have been affected by the mixed effects of the diverse properties of odorants: (1) sweet, pungent odor of toluene (odor threshold of $2.9 \mathrm{ppm}$ ), (2) acetone-like odor of methyl ethyl ketone (odor threshold of $5.4 \mathrm{ppm}$ ), and (3) pleasant, fruity odor of ethyl acetate (odor threshold of 3.9 ppm) [29-31]. On the other hand, some compounds with high concentrations like ethyl alcohol (1.43 ppm) were also observed from samples with a relatively small D/T ratio (65.8). Similarly, in another bag, high TVOC value (114 ppmC) was coinciding with high concentrations of these same three compounds, namely, toluene (41.7 ppm), methyl ethyl ketone (31.8 ppm), and ethyl acetate (36 ppm). In another bag, high concentrations of TVOC (135.4 ppmC) were also accompanied by high level of methyl ethyl ketone ( $28.9 \mathrm{ppm})$, ethyl alcohol (71.3 ppm), ethyl acetate (24.3 ppm), and toluene ( $7 \mathrm{ppm})$. Thus, it is seen that the occurrence of normally high concentrations of certain VOCs (toluene, methyl ethyl ketone, and ethyl acetate) is often directly linked to high TVOC values in the bags. This experimental finding is supported by the strong correlations between TVOC and individual components (e.g., toluene $=0.79(P=1.43 E-06)$, methylethyl ketone $=$ $0.93(P=9.62 E-12)$, and ethyl acetate $=0.97(P=1.15 E-15)($ Table 4$)$. 
TABLE 3: Statistical summary of volatile organic compounds found in used Tedlar bags (ppb unit).

(a) Polar compounds

\begin{tabular}{lcccccc}
\hline Order & Compounds $^{\mathrm{a}}$ & Mean $^{\mathrm{b}}$ & $\mathrm{SD}^{\mathrm{c}}$ & Min & Max & $N^{\mathrm{d}}$ \\
\hline 1 & AA & 19.1 & 15.9 & 3.75 & 70.1 & 26 \\
2 & ATM & 106 & 78.7 & 28.6 & 380 & 26 \\
3 & AAD & 1.20 & 1.51 & 0.30 & 5.98 & 11 \\
4 & AT & 85.9 & 52.1 & 0.21 & 241 & 24 \\
5 & AN & 364 & 140 & 0.45 & 800 & 25 \\
6 & BT & 108.4 & 313 & 0.13 & 1282 & 14 \\
7 & DC & 46.2 & 18.8 & 15.0 & 86.5 & 26 \\
8 & EAC & 1152 & 3359 & 0.10 & 14080 & 23 \\
9 & EA & 1463 & 6979 & 19.7 & 35675 & 26 \\
10 & IA & 47.7 & 119 & 0.20 & 621 & 25 \\
11 & MB & 152.3 & 453 & 0.08 & 2217 & 11 \\
12 & MEK & 1467 & 4769 & 0.14 & 22556 & 24 \\
13 & PT & 164.1 & 481 & 0.08 & 2127 & 11 \\
14 & PH & 88.0 & 74.0 & 0.06 & 334 & 25 \\
15 & THF & 25.1 & 24.3 & 0.13 & 109 & 24 \\
\hline
\end{tabular}

(b) Nonpolar compounds

\begin{tabular}{lcccccc}
\hline Order & Compounds $^{\mathrm{a}}$ & Mean $^{\mathrm{b}}$ & $\mathrm{SD}^{\mathrm{c}}$ & Min & Max & $N^{\mathrm{d}}$ \\
\hline 1 & $\mathrm{~B}$ & 4.76 & 10.6 & 0.07 & 48.0 & 18 \\
2 & $\mathrm{COS}$ & 4.48 & 5.21 & 0.61 & 23.1 & 14 \\
3 & $\mathrm{DO}$ & 3.80 & 4.70 & 0.16 & 14.7 & 14 \\
4 & $\mathrm{~EB}$ & 11.7 & 35.1 & 0.04 & 138 & 16 \\
5 & $\mathrm{IB}$ & 6.74 & 8.16 & 0.16 & 27.4 & 14 \\
6 & $\mathrm{MA}$ & 4.45 & 9.80 & 0.16 & 49.4 & 14 \\
7 & $\mathrm{DD}$ & 11.2 & 14.0 & 0.02 & 45.1 & 19 \\
8 & OT & 5.75 & 16.7 & 0.04 & 84.8 & 12 \\
9 & $\mathrm{p}-\mathrm{X}$ & 23.5 & 96.2 & 0.05 & 494 & 23 \\
10 & $\mathrm{~T}$ & 448 & 1328 & 0.06 & 5969 & 25 \\
\hline
\end{tabular}

(c) Reference parameters

\begin{tabular}{lccccc}
\hline 1 & D/T ratio & 323 & 503 & 44.8 & 2080 \\
2 & TVOC & 21155 & 45356 & 1503 & 174092 \\
\hline
\end{tabular}

${ }^{a}$ Acronyms of the compounds used here can be found in Table 1.

${ }^{\mathrm{b}}$ For the data measured below detection limit (DL), one half of DL was used to compute the mean.

${ }^{\mathrm{c}}$ Standard deviation.

${ }^{\mathrm{d}}$ Number of values above detection limit (among 26 bags).

Among the list of compounds detected from the used Tedlar bags, the nonpolar compound, toluene is strongly correlated with polar compounds such as methyl ethyl ketone $(r=0.73, P=2.04 E-05)$, isopropyl alcohol $(r=0.92, P=4.44 E-11)$, ethyl acetate $(r=0.86, P=2.23 E-08)$, and acetamide $(0.74$, $P=1.79 E-05)$ (Table 5). Likewise, $p$-xylene is also found to record a strong correlation with $n$-octane $(r=0.96, P=2.32 E-15)$. In all of these cases, their correlations are statistically significant $(P<0.01)$. It is thus most likely that, because at one or more particular sampling points, these compounds should have occurred similarly higher concentrations due to similar source properties. 


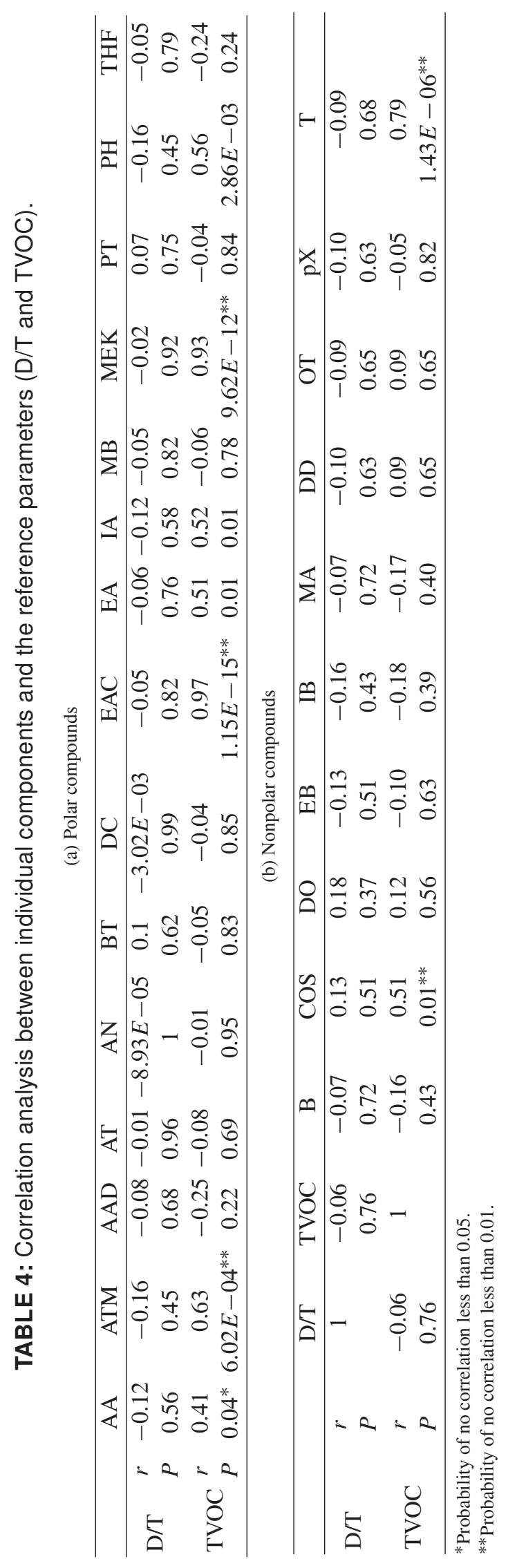




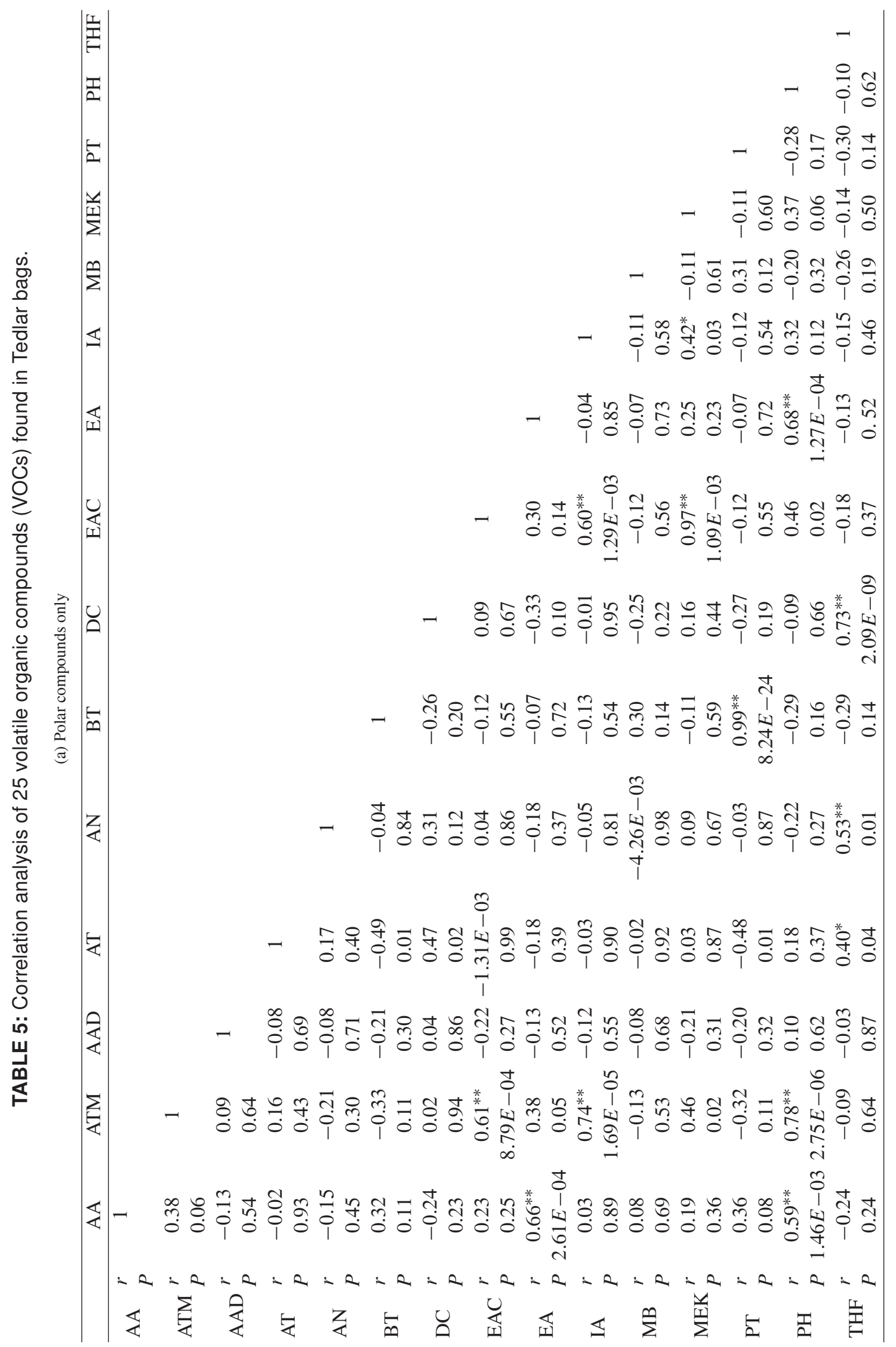




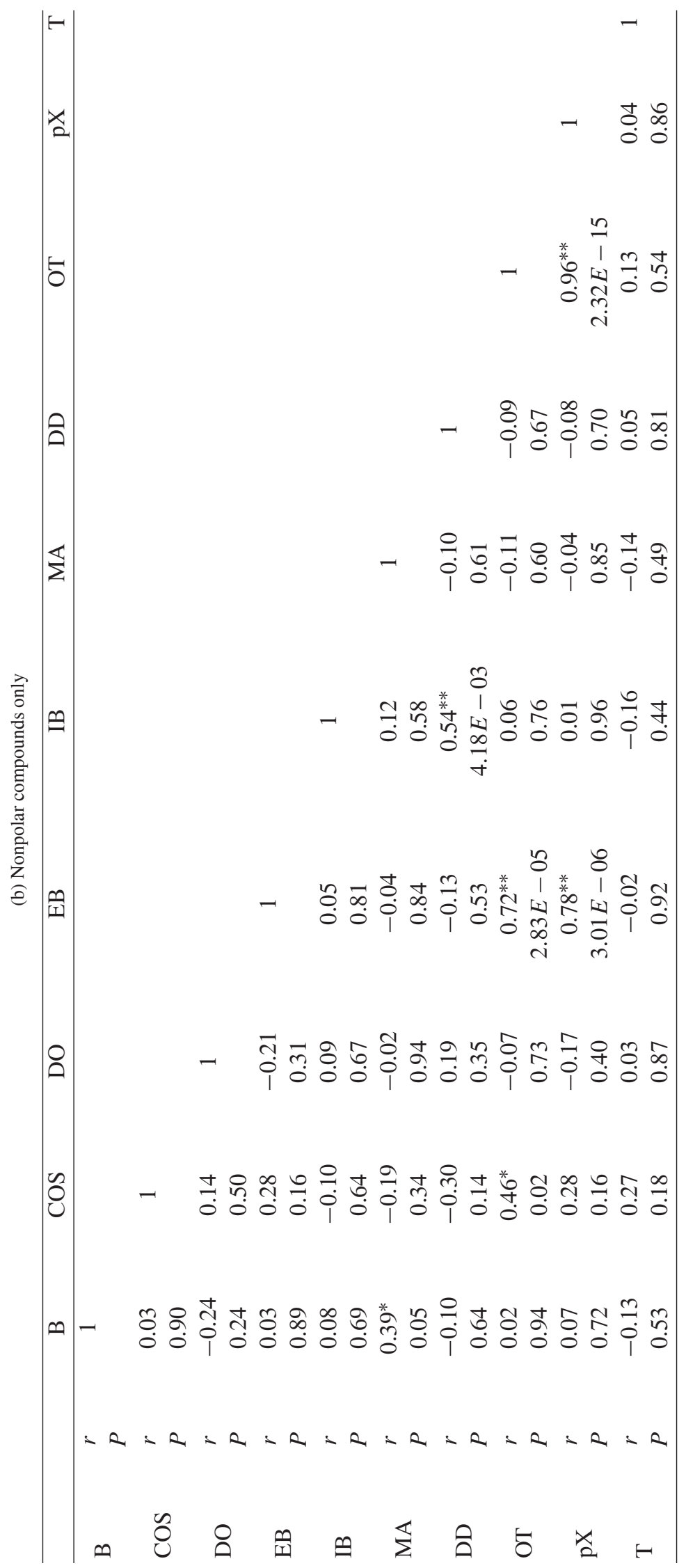




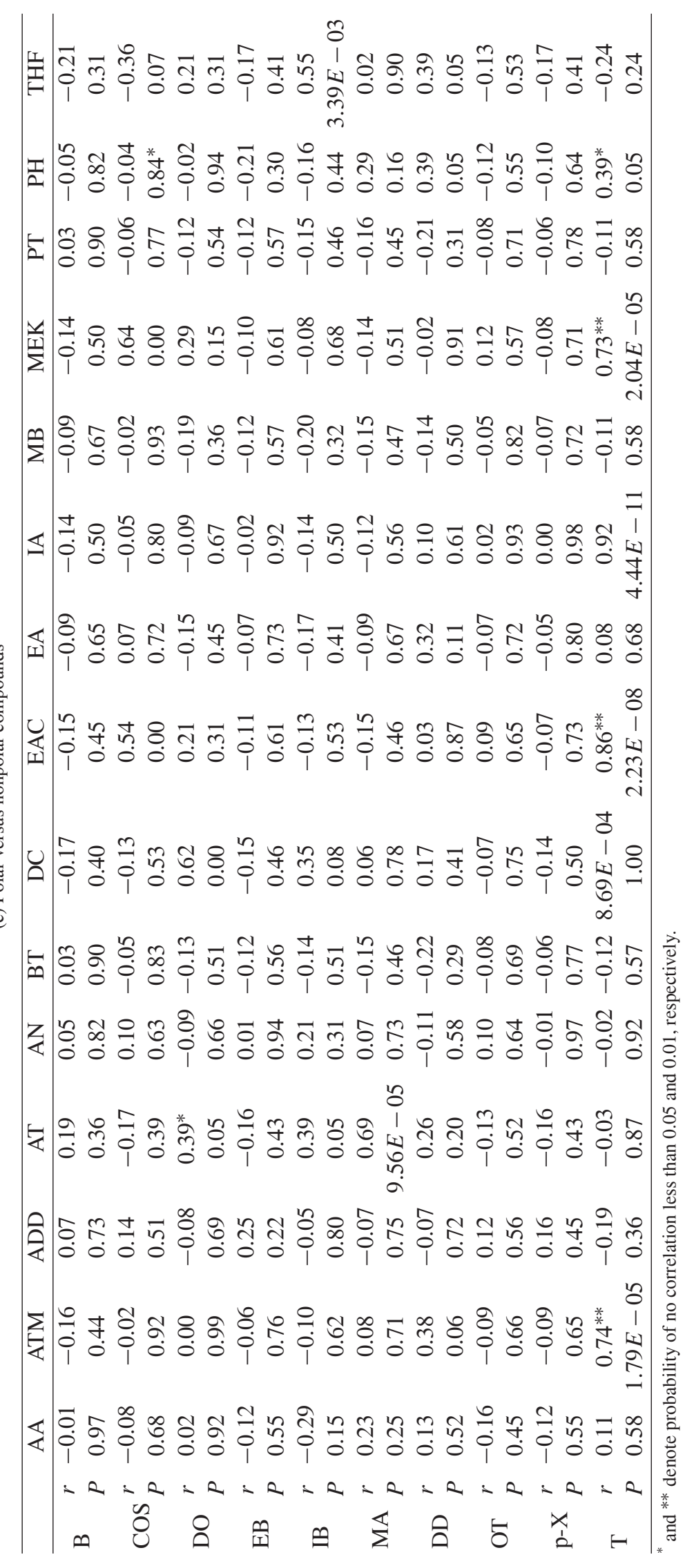




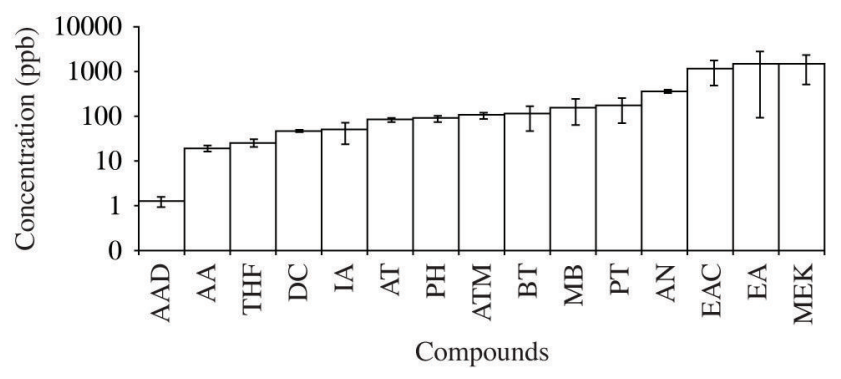

(a) Polar compounds

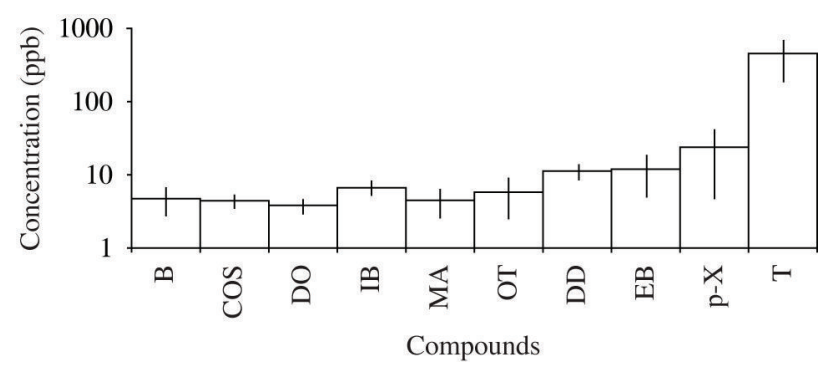

(b) Nonpolar compounds

FIGURE 1: Comparison of the mean VOCs levels found in used Tedlar bags (refer to Table 1 for acronyms of the compounds.)

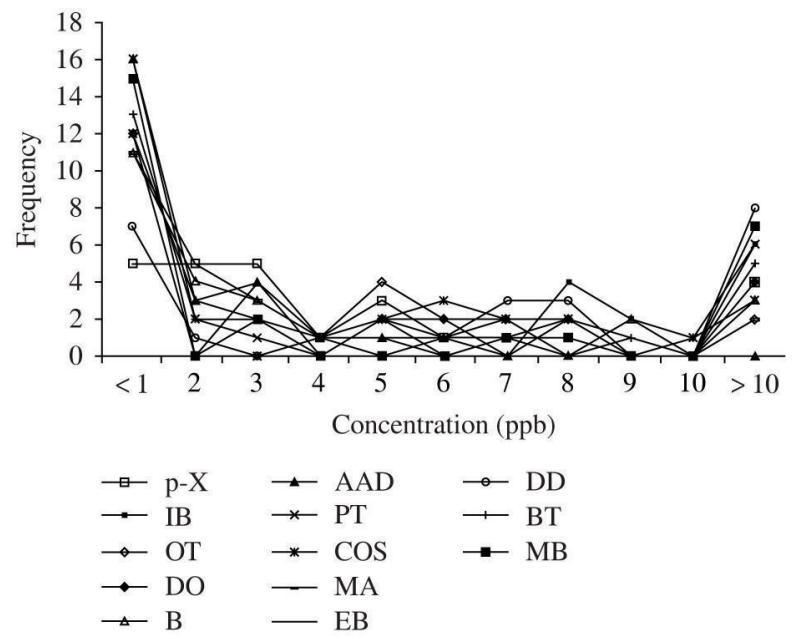

(a) Type 1

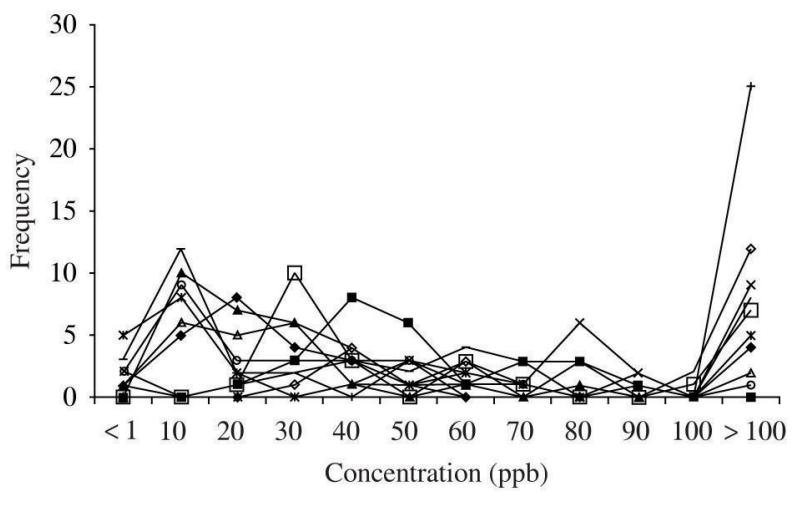

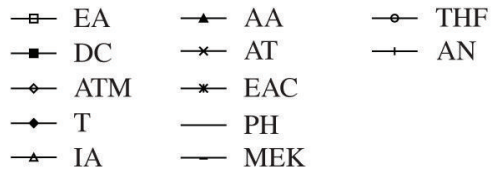

(b) Type 2

FIGURE 2: Frequency distribution of VOCs found in used Tedlar bags. (Compounds are grouped by their relative frequency: refer to Table 1 for acronyms of the compounds.)

\subsection{Adsorption Study}

The adsorptive tendency of a compound is largely dependent on electrostatic forces influenced by hydrogen bonding, polarity, and van der Waal's interactions [5]. In our study, concentrations of 3 polar compounds (methyl ethyl ketone, ethyl alcohol, and ethyl acetate) showed noticeably higher abundances than the rest. Of these three compounds, only ethyl alcohol is capable of forming hydrogen bonding. Chemical interactions between functional groups on adsorbent and adsorbate molecules may be the key criteria for the bond 
formation. However, due to the relative inertness of the polyvinyl fluoride polymer film, such possibilities of bond formation will be nullified. There is also evidence that the most important sites for adsorption can be the fittings rather than the Tedlar itself [32]. Wang et al. [4] also found that almost all loses of compounds in their study were due to adsorption onto the stainless-steel hose valve of the Tedlar bags.

The results of our study suggest that polar compounds are released more effectively from the Tedlar film materials than nonpolar compounds. Likewise, Trabue et al. [12] determined certain polar compounds at appreciable levels such as phenol $(0.29 \mathrm{ppb})$, acetic acid $(0.37 \mathrm{ppb})$, and acetamide $(0.75 \mathrm{ppb})$ in Tedlar bags used for the sampling in animal production facilities. They also found that compounds with the lowodor-threshold values were sorbed on Tedlar surfaces more strongly. The results derived from these previous studies are consistent with our findings in a number of respects.

\section{CONCLUSION}

In this research, we analyzed a number of used Tedlar bags for the level of leachable VOCs to learn more about the relative reactivity of different VOCs with Tedlar film. It is recognized that the level of leaching is fairly insignificant for nonpolar compounds relative to their polar counterparts. The mean concentrations of all nonpolar compounds found in the Tedlar bags (except toluene) like benzene, $p$-xylene, COS, isobutene, $n$-octane, ethyl benzene, and $n$-dodecane are relatively low at 4.76, 23.5, 4.48, 6.74, 5.75, 11.7, and $11.2 \mathrm{ppb}$, respectively. The mean concentration of toluene is however unusually large, with the highest mean value of all nonpolar compounds (448 ppb).

As expected, the mean concentrations of highly polar compounds (like methyl ethyl ketone, ethyl alcohol, and ethyl acetate) are very high $(1.47,1.46$, and $1.15 \mathrm{ppm}$, resp.). In addition, several polar compounds (like acetaldehyde, ethyl alcohol, dichloromethane, acetamide, and phenol) were quantified consistently in all the bags. Moreover, two aldehydes (3-methylbutanal and $n$-pentanal) with similar polarity are also found in a highly similar range (152 and $164 \mathrm{ppb}$, resp.). Both the polar and nonpolar compounds are found to follow similar trends in relative frequency patterns, although their levels are greatly distinguishable in absolute terms. The results of the correlation analysis indicated the relatively high abundance of strongly correlated pairs among polar compounds, while it is not the case for nonpolar compounds. The TVOC concentration found from individual bags also varied widely (1.5 to $174 \mathrm{ppmC}$ ). The results of the ADS test, expressed as D/T ratio, also varied in a wide range from 44.8 to 2080 . In some cases, high $\mathrm{D} / \mathrm{T}$ ratio values are supported by high concentrations of odorous compounds. The $\mathrm{D} / \mathrm{T}$ ratio is however often not directly correlated with the concentration of the dominant species. In contrast, TVOC values generally showed a good correlation with the concentrations of dominant component. As such, the overall results of this study consistently indicate that polar compounds can be subject to negative bias more significantly (due to their affinity on the Tedlar bags) than nonpolar compounds (other than toluene). Thus, we must take caution on the nature and extent of bias when sampling and analyzing VOCs based on grab sampling methods like Tedlar bag sampler. Consequently, the interactive relationship between sampler and different VOC types should be evaluated systematically to reduce analytical variability and biases involved in the sampling stage.

\section{ACKNOWLEDGMENT}

This study was supported by a National Research Foundation of Korea (NRF) Grant funded by the Ministry of Education, Science and Technology (MEST) (no. 2009-0093848).

\section{REFERENCES}

[1] B. M. Broderick and I. S. Marnane, "A comparison of the C2-C9 hydrocarbon compositions of vehicle fuels and urban air in Dublin, Ireland," Atmospheric Environment, vol. 36, no. 6, pp. 975-986, 2002. 
[2] United States environmental protection agency (EPA), 2010, http://www.epa.gov/iaq/voc.html.

[3] M. M. L. Steeghs, S. M. Cristescu, and F. J. M. Harren, "The suitability of Tedlar bags for breath sampling in medical diagnostic research," Physiological Measurement, vol. 28, no. 1, pp. 73-84, 2007.

[4] Y. Wang, T. S. Raihala, A. P. Jackman, and R. S. T. John, "Use of Tedlar bags in VOC testing and storage: evidence of significant VOC losses," Environmental Science and Technology, vol. 30, no. 10, pp. 3115-3117, 1996.

[5] L. J. McGarvey and C. V. Shorten, "The effects of adsorption on the reusability of Tedlar@ air sampling bags," American Industrial Hygiene Association Journal, vol. 61, no. 3, pp. 375-380, 2000.

[6] US EPA. Method 18-VOC by GC, 2011, http://www.epa.gov/ttnemc01/methods/method18.html\#isd.

[7] J. C. Polasek and J. A. Bullin, "Evaluation of bag sequential sampling technique for ambient air analysis," ES and T Contents, vol. 12, no. 6, pp. 708-712, 1978.

[8] N. A. Kelly, K. L. Olson, and C. A. Wong, "Tests for fluorocarbon and other organic vapor release by fluorocarbon film bags," Environmental Science and Technology, vol. 19, no. 4, pp. 361-364, 1985.

[9] J. C. Posner and W. J. Woodfin, "Sampling with gas bags I: losses of analyte with time," Applied Industrial Hygiene, vol. 1, pp. 163-168, 1986.

[10] J. M. Andino and J. W. Butler, "A study of the stability of methanol-fueled vehicle emissions in Tedlar bags," Environmental Science and Technology, vol. 25, no. 9, pp. 1644-1646, 1991.

[11] S. S. Parmar, "A study of "holding times" for $\mathrm{H}_{2} \mathrm{~S}, \mathrm{COS}$, and $\mathrm{CH}_{3} \mathrm{SH}$ samples (gas phase) in different containers," in Proceedings of the EPA/ Air and Waste Management Association's Air Toxics Meeting, EPA, Raleigh, NC, USA, 1996.

[12] S. L. Trabue, J. C. Anhalt, and J. A. Zahn, "Bias of tedlar bags in the measurement of agricultural odorants," Journal of Environmental Quality, vol. 35, no. 5, pp. 1668-1677, 2006.

[13] M. J. Barcelona, J. A. Helfrich, and E. E. Garske, "Sampling tubing effects on groundwater samples," Analytical Chemistry, vol. 57, no. 2, pp. 460-464, 1985.

[14] G. W. Reynolds, J. T. Hoff, and R. W. Gillham, "Sampling bias caused by materials used to monitor halocarbons in groundwater," Environmental Science and Technology, vol. 24, no. 1, pp. 135-142, 1990.

[15] J. K. Park and M. Nibras, "Mass flux of organic chemicals through polyethylene geomembranes," Water Environment Research, vol. 65, no. 3, pp. 227-237, 1993.

[16] J. C. Pau, J. E. Knoll, and M. R. Midgett, "A Tedlar bag sampling system for toxic organic compounds in source emission sampling and analysis," Journal of the Air and Waste Management Association, vol. 41, no. 8, pp. 1095-1097, 1991.

[17] M. Ajhar, B. Wens, K. H. Stollenwerk, G. Spalding, S. Yüce, and T. Melin, "Suitability of Tedlar gas sampling bags for siloxane quantification in landfill gas," Talanta, vol. 82, no. 1, pp. 92-98, 2010.

[18] K. H. Kim and S. Y. Park, "A comparative analysis of malodor samples between direct (olfactometry) and indirect (instrumental) methods," Atmospheric Environment, vol. 42, no. 20, pp. 5061-5070, 2008.

[19] D. G. Guadagni, R. G. Buttery, and J. Harris, "Odour intensities of hop oil components," Journal of the Science of Food and Agriculture, vol. 17, no. 3, pp. 142-144, 1966.

[20] T. E. Acree, J. Barnard, and D. G. Cunningham, "A procedure for the sensory analysis of gas chromatographic effluents," Food Chemistry, vol. 14, no. 4, pp. 273-286, 1984.

[21] Korean Ministry of Environment (KMOE), 2005, Annual Report of Ambient Air Quality in Korea.

[22] Y. Nagata, "Measurement of odor threshold by triangular odor bag method. Odor measurement review," Japan Ministry of Environment, Government of Japan, pp. 118-127, 2003.

[23] J. W. Ahn, S. K. Pandey, and K.-H. Kim, "Comparison of GC-MS calibration properties of volatile organic compounds between direct injection and solid phase microextraction," The Journal of Chromatographic Science, vol. 49, pp. 19-28, 2011.

[24] D. B. Parker, Z. L. Perschbacher-Buser, N. A. Cole, and J. A. Koziel, "Recovery of agricultural odors and odorous compounds from polyvinyl fluoride film bags," Sensors, vol. 10, no. 9, pp. 8536-8552, 2010.

[25] R. E. Chase, "Properties and manufacture of Tedlar Polyvinyl fluoride film," ERC Technical report VERL, Ford Research Laboratory, 2001.

[26] "DuPontTM Tedlarß polyvinyl fluoride film: chemical properties, optical properties, and weatherability performance," 2010, http://www2.dupont.com/Tedlar_PVF_Film/en_US/assets/downloads/pdf/h49725.pdf. 
[27] A. Amann, "Breath analysis for medical diagnosis and therapeutic monitoring," Spectroscopy Europe, vol. 17, no. 3, pp. 18-20, 2005.

[28] ASTM (American Society for Testing and Materials), "Determination of odor and taste thresholds by a forced choice ascending concentration series method of limits," Method E, pp. 679-691, 1991.

[29] J. A. Nicell, "Expressions to relate population responses to odor concentration," Atmospheric Environment, vol. 37, no. 35, pp. 4955-4964, 2003.

[30] Agency for Toxic Substances and Disease Registry (ATSDR), Toxicological Profile for Toluene (Update), US Public Health Service, US Department of Health and Human Services, Atlanta, Ga, USA, 1994.

[31] J. E. Amoore and E. Hautala, "Odor as an air to chemical safety: odor thresholds compared with threshold limit values and volatilities for 214 industrial chemicals in air and water dilution," Journal of Applied Toxicology, vol. 3, no. 6, pp. 272-290, 1983.

[32] A. M. H. Debruyn and J. B. Rasmussen, "Applicability of Tedlar(TM) bags to aqueous sampling for ambient toxicity testing: adsorption of trace metals," Environmental Toxicology and Chemistry, vol. 18, no. 9, pp. 19321933, 1999.

\section{This article should be cited as follows:}

Samik Ghosh, Ki-Hyun Kim, and Jong Ryeul Sohn, "Some Insights into Analytical Bias Involved in the Application of Grab Sampling for Volatile Organic Compounds: A Case Study against Used Tedlar Bags," TheScientificWorldJOURNAL, vol. 11, pp. 2160-2177, 2011. 

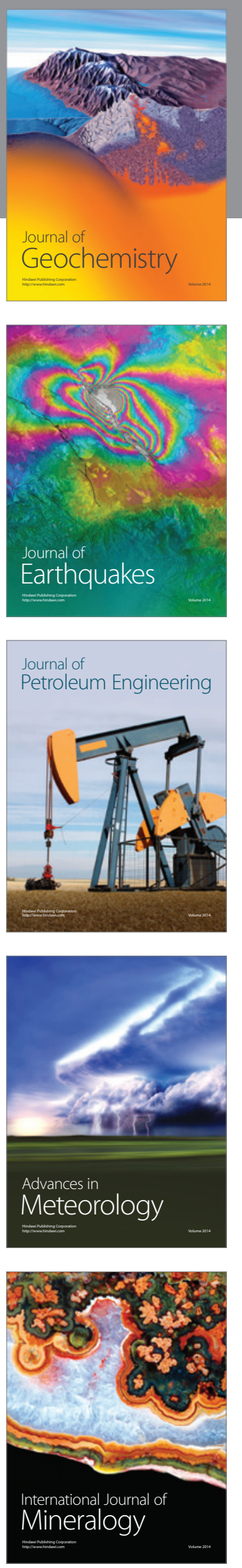
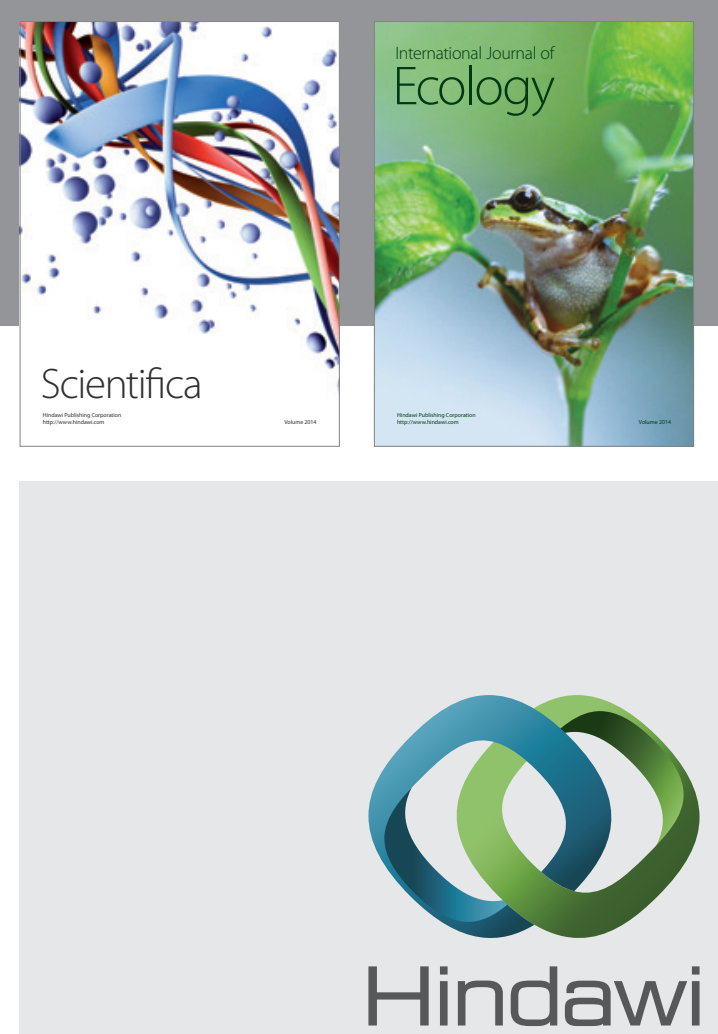

Submit your manuscripts at http://www.hindawi.com
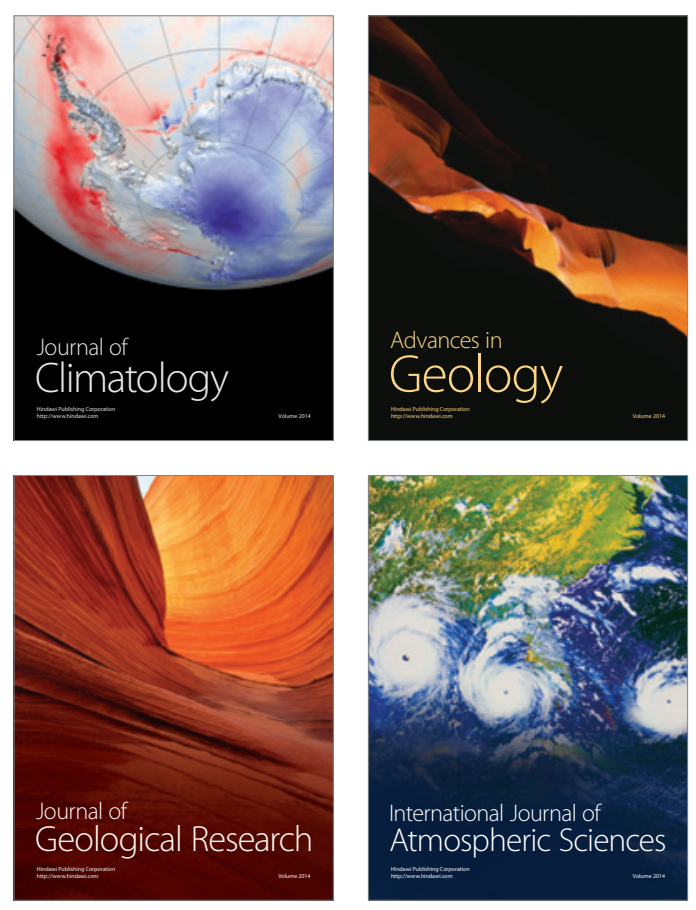
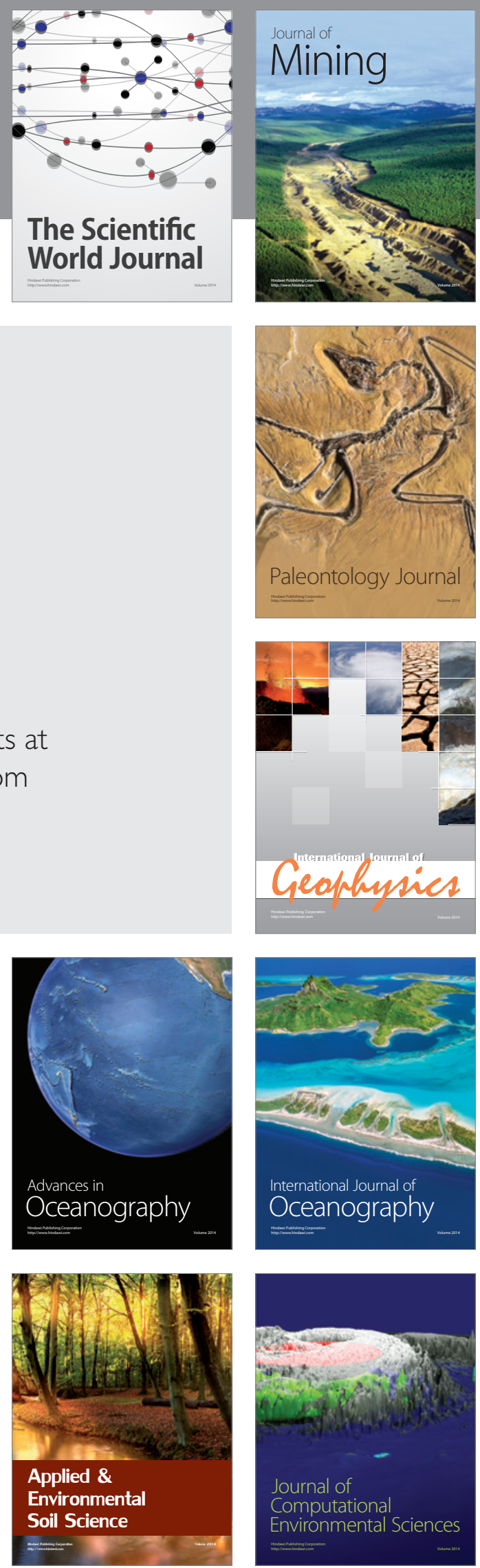